\title{
Assessing Knowledge, Attitude and Practices of Primary Health Care Physicians Towards Screening Patients for Hypertension in Cairo.
}

\author{
Ayman S. Abdelhady \\ Community Medicine Department, Faculty of Medicine, Al-Azhar University.
}

\begin{abstract}
Introduction : Hypertension (HTN) is a common serious health problem associated with high morbidity and mortality rates. At the same time ,HTN is widely prevalent all over the world including Egypt. For many people, the primary care physician is their first point of contact with the health care system, as well as their main source of preventive and essential care.

Objective: Assessing knowledge, attitude and practices of primary health care physicians towards screening patients for hypertension in Cairo.

Methodology:A cross-sectional study, conducted in the primary health care centres (PHCC) in Nasr city, which was chosen randomly to represent Cairo city, where all doctors working in these centres were asked to complete a self administered structured and open ended questionnaire contained the relevant variables :

Results: About $90 \%$ of the studied physicians were convinced with the importance of routine measuring blood pressure for risky patients and 79\% stated that role of the PHC physician should be the early detection of HTN. As regards knowledge towards HTN items, only $23.5 \%$ knew the prevalence and $18.5 \%$ knew the most recent definition and grading. The practices of the doctors towards screening patients for HTN ,showed that only $63.9 \%$ of the doctors usually perform accurate and enough procedures to diagnose HTN patients and $46.2 \%$ routinely screen patients around forty years old while only $43.7 \%$ were regularly checking up the accuracy of the used sphygmomanometers .

Conclusion: The participating physicians had poor knowledge towards some important items especially the prevalence and new classification of HTN. Their practices were not optimal as regards the accurate diagnosis of HTN and routine checkup and measuring blood pressure for people attending the PHC clinics. Recommendations to manage these defects were suggested.
\end{abstract}

\section{Introduction}

Hypertension (HTN) is a common serious health problem associated with high morbidity and mortality rates (El-Khashab, 2002).

One old and most prevailing definition and classification of HTN recommended a systolic blood pressure (SBP) $>140 \mathrm{mmHg}$ or diastolic blood pressure (DBP) of 90 or more for the starting point of HTN of mild degree, ( DBP) of 105-114 $\mathrm{mmHg}$ for moderate HTN and (DBP) of $\geq$ $115 \mathrm{mmHg}$ for severe HTN (National Heart, Lung \& Blood Institute US, 1993).

The most recent definition and classification of HTN emphasized the importance of assessing the risk factors, the patient may have. This classification considered blood pressure of the person to be normal below $120 / 80 \mathrm{mmHg}$, prehypertensive at BP:120-139/80-89 mm $\mathrm{Hg}$, hypertensive (stage 1) at BP: 140-159/9099 and hypertensive (stage 2) with BP $\geq 160 / 100$. Treatment should be started to $\mathrm{BP}<140 / 90$ or $\mathrm{BP}<130 / 80$ in patients with diabetes or chronic kidney disease (National Heart, Lung \& Blood Institute US, 2004).

Evidence from the Egyptian Hypertension National Project on a random sample of 6733 subjects in six Egyptian governorates, revealed that the overall prevalence of hypertension is unusually 
high $(30.4 \%)$ for a developing country and $26 \%$ of Egyptian adults suffer from high blood pressure, with higher prevalence among elderly subjects $(71 \%$ for elderly females and 55\% for elderly men). Cardiovascular diseases are now the main cause of death, being responsible for $42.5 \%$ of all deaths, while 20 years earlier they accounted for only $12.4 \%$ of mortality ( Khalil, 1997 ).

Many studies, published between 1980 and 2003, have concluded that the true global prevalence of hypertension is approximately $30 \%$. One quarter of all adults in the United States had hypertension (systolic $\mathrm{BP} \geq 140 \mathrm{mmHg}$ or diastolic $\mathrm{BP} \geq 90$ $\mathrm{mmHg}$ or use of antihypertensive medication) ( Wang \& Wang, 2004). The corresponding percentage was somewhat lower (14.4\%) for adults in China during 1991. In Eastern Meditreanean region HTN was estimated to affect $20-26 \%$ of population above 35 years. In Saudi Arabia, the prevalence was 4-17\% among males and 3-13\% among females (Kalantan et al., 2001 ; Ibrahim , 1996 ).

Attention should be focused on the primary prevention of hypertension in order to deal with this major problem. Most preventive health care and screening for early disease detection and management take place in the primary health care setting at the community level. These primary health care (PHC) centres, to which people can self refer, also provide the bulk of ongoing management and care. It is estimated that $80 \%$ of front-line health care is provided at the community level where PHC centres form the backbone of the health care system ( WHO, 2003).In 1995, the World Hypertension League Declaration concerning hypertension control in developing countries stated: "Much can be achieved with modest means if there is adequate society support, and when control measures are firmly based in primary health care"(Alaszewski et al., 2004 ; Bodenheimer et al.,2002).

For many people, the primary care physician (PCP) is their first point of contact with the health care system, as well as their main source of preventive and essential care (Macinko et al., 2003 ). A growing body of literature argues that an effective approach to meeting the needs of chronically ill patients is to improve the delivery of primary care (Bonomi et al., 2002 ).

The majority of HTN cases are asymptomatic which could be unrecognized and untreated leading to a significantly higher risk of heart and renal diseases and strokes .The absence of symptoms in most cases of (HTN) even at its highest and most dangerous levels has a profound implications for the effective management of the condition in the primary care, where the "rule of halves "may be applied which implies that half of the cases will be discovered; half of them will be treated and only half of those receiving treatment will be adequately controlled (Baicker and Chandra ,2004).

Screening for HTN aims at detecting occult diseases in asymptomatic patient by concentrating on those with risk factors. Identification of risk factors allows the early intervention to prevent disease occurrence. Measurement of BP as a screening technique is easy, simple, cheap and acceptable (Whelton et al., 2002 ).

The PHC system is easily accessible and can cover a major section in the community, so screening for HTN through these (PHC) centres is suitable and appropriate ( WHO, 2003 ).

\section{Aim of the Work}

The aim of this study was to assess the knowledge, attitude and practices of (PHC) physicians in relation to screening their patients for HTN in Cairo city.

\section{Methodology}

-This study was a cross-sectional study, conducted in the primary health care centres (PHCC) in Nasr city which was chosen randomly to represent Cairo city, where all doctors working in these centres (5 centers) were asked to complete a structured and open ended self administered questionnaire containing the relevant variables ( during December 2005) : 


\section{Ayman S. Abdelhady}

A. Sociodemographic data of the participating physicians including the medical degree and years of experience in (PHC).

B. Knowledge of the physicians towards HTN: etiology, risk factors, definition $\&$ grading, prevalence and complications of HTN.

C. Attitude of the physicians towards measuring blood pressure.

D. Practices of the participating physicians towards HTN: the following points were investigated:

1. Accurate and enough procedures are essential to diagnose HTN:

*Measurement: -position (sitting after resting 5 minutes and the patient should not have smoked or drunk coffee or tea or had food 30 minutes before measurement).

-Adequate size of the cuff used.

-Repetition of the measurement: 2 readings are taken with 2 minutes apart in each visit (the lowest is taken), BP should be measured 3 times at interval 1-2 days before the person is labelled as a hypertensive.

*History taking: existing disease (angina, diabetes,..), risk factor (major: smoking, hyperlipidemia ... minor : family history of HTN, sedentary life style)

*Detailed physical examination: general (e.g. for body weight) and local (e.g. chest \& heart).

*Investigations: as renal function tests and ECG.

2. Whether the physician regularly checks up the accuracy of the used sphygmomanometers?

3. If the physician measures the BP every time the hypertensive patient attends the clinic?

4. Routine measuring BP for patients with risky factors attending the clinic every visit especially obese, diabetic and those with renal diseases and those around forty years old ( to be followed up every 1-2 year before 40 and every 3-6 months after 40 years ) (Whelton et al., 2002 ).

-The questionnaire was first piloted in one centre and data were collected and analyzed for interpretation, using SPSS program, version 9.05. The $\mathrm{x}^{2}$ test was used to examine differences between variables.

\section{Results}

A total number of 119 primary health care (PHC) physicians have participated in the study. Their ages ranged between 29 and 54 years with mean age and SD: $40 \pm$ 6.3 years. Of the total number, only 48 physicians $(40 \%)$ had postgraduate qualifications in the form of diploma, master degree and family medicine fellowship.

Table (1): showed the accuracy of knowledge of the physician towards different hypertension items, where the correct answer was obtained by $(92.4 \%)$ of the physicians for complications, $(89.9 \%)$ for risk factors , $(63.9 \%)$ for etiology , and $(85.7 \%)$ for old definition and grading only , while only $(23.5 \%)$ knew the prevalence and $(18.5 \%)$ knew the old and most recent definition and grading of (HTN) .It was also noticed that females knew the most recent definition and grading of HTN better than males $(25.7 \%$ vs $6.7 \%$, and also those of experience less than ten years $(35.5 \%)$ did better than those of more than ten years $(12.5 \%)$ with statistically significant differences.

Table (2): revealed that majority of the participating physicians had a high level of favorable attitude towards measuring blood pressure, where the percentage of agreement was $(90.8 \%)$ for the principle "periodic check and follow up is necessary to detect any disease in general and especially for risky patients",(79\%) agreed with the statement :The role of the (PHC) physician should be the early detection of (HTN), and (77.3\%) stated that " screening of HTN is worthy for both the doctor and the patient", while job satisfaction inside the PHCC was reported by only (56.3\%) of the physicians.

In table (3), the practices of the physicians showed that $90.8 \%$ of them usually measure the blood pressure every time the hypertensive patient attends the clinic, (83.2\%) routinely measure blood 
pressure for risky patients ,and (63.9\%) mentioned that they accurately carry out diagnostic procedures for HTN while only $(46.2 \%)$ routinely measure the blood pressure for patient around forty years old and $(43.7 \%)$ stated that they regularly check up the accuracy of the sphygmomanometers used in measuring BP.

Table (1): Knowledge of The Studied Physicians Towards (HTN)* Versus Their Sociodemographic Data

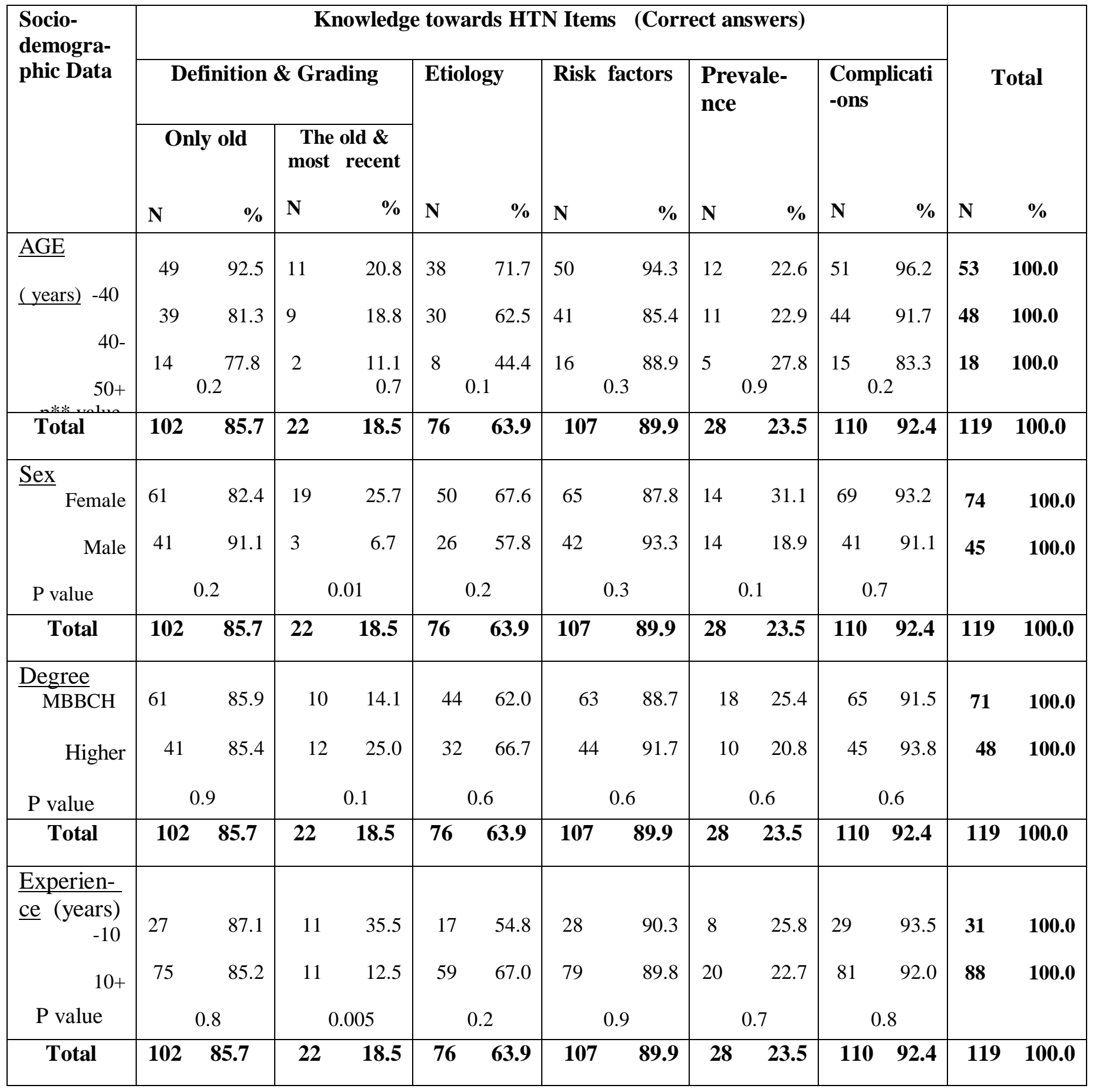


Table (2):Favorable Attitude of the Studied PHC* Physicians towards Measuring Blood Pressure (BP) Versus Their Sociodemographic Data.

\begin{tabular}{|c|c|c|c|c|c|c|c|c|c|c|c|c|}
\hline \multirow{2}{*}{$\begin{array}{l}\text { Sociodemo- } \\
\text { grahic Data }\end{array}$} & \multicolumn{10}{|c|}{ Favorable attitude towards measuring BP } & \multirow{2}{*}{\multicolumn{2}{|c|}{ Total }} \\
\hline & \multicolumn{2}{|c|}{$\begin{array}{l}\text { Job satisfaction } \\
\text { inside the PHC, } \\
\text { especially in } \\
\text { dealing with } \\
\text { chronic diseases }\end{array}$} & \multicolumn{2}{|c|}{$\begin{array}{l}\text { Role of PHC } \\
\text { doctor is the } \\
\text { early } \\
\text { detection of } \\
\text { hypertension }\end{array}$} & \multicolumn{2}{|c|}{$\begin{array}{l}\text { Screening for } \\
\text { hypertension } \\
\text { is worthy for } \\
\text { the patient } \\
\text { and doctor }\end{array}$} & \multicolumn{2}{|c|}{$\begin{array}{l}\text { Routine } \\
\text { measuring } \\
\text { blood pressure } \\
\text { should be done } \\
\text { for risk factors } \\
\text { patients }\end{array}$} & \multicolumn{2}{|c|}{$\begin{array}{l}\text { measuring } \\
\text { BP should be } \\
\text { done as it is } \\
\text { quick ,easy } \\
\text { and practical } \\
\text { test }\end{array}$} & & \\
\hline AGE (year) & & & & & & & & & & & & \\
\hline$-<40$ & 26 & 49.1 & 43 & 81.1 & 40 & 75.5 & 46 & 86.8 & 49 & 92.5 & 53 & 100.0 \\
\hline 40- & 35 & 72.9 & 36 & 75.0 & 38 & 79.2 & 44 & 91.7 & 47 & 97.9 & 48 & 100.0 \\
\hline 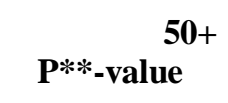 & 6 & 33.3 & 15 & 83.3 & 14 & 77.8 & 18 & 100.0 & 17 & 594.4 & 18 & 100.0 \\
\hline Total & 67 & 56.3 & 94 & 79.0 & 92 & 77.3 & 108 & 90.8 & 113 & 95.0 & 119 & 100.0 \\
\hline$\underline{\text { SEX }} \quad$ Male & 24 & 53.3 & 37 & 82.2 & 39 & 86.7 & 41 & 91.1 & 40 & 88.9 & 45 & 100.0 \\
\hline${ }_{\text {P-value }}^{\text {Female }}$ & 43 & 58.1 & 57 & 77.0 & 53 & 71.6 & 67 & 90.5 & 73 & $18^{98.6}$ & 74 & 100.0 \\
\hline Total & 67 & 56.3 & 94 & 79.0 & 92 & 77.3 & 108 & 90.8 & 113 & 95.0 & 119 & 100.0 \\
\hline DEGREE & & & & & & & & & & & & \\
\hline МВВСН & 40 & 56.3 & 57 & 80.3 & 58 & 81.7 & 64 & 90.1 & 68 & 95.8 & 71 & 100.0 \\
\hline $\begin{array}{l}\text { Higher } \\
\text { P-value }\end{array}$ & 27 & 56.3 & 37 & 77.1 & 34 & 70.8 & 44 & 91.7 & & $5^{93.8}$ & 48 & 100.0 \\
\hline Total & 67 & 56.3 & 94 & 79.0 & 92 & 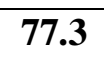 & 108 & 90.8 & 113 & 95.0 & 119 & 100.0 \\
\hline$\frac{\text { Experience }}{(\text { year })<10}$ & 18 & 58.1 & 21 & 67.7 & 25 & 80.6 & 25 & 80.6 & 29 & 93.5 & 31 & 100.0 \\
\hline P-value ${ }^{10+}$ & 49 & 55.7 & 73 & 83.0 & 67 & 76.1 & 83 & 94.3 & 84 & 95.5 & 88 & 100.0 \\
\hline Total & 67 & 56.3 & 94 & 79.0 & 92 & 77.3 & 108 & 90.8 & 113 & 95.0 & 119 & 100.0 \\
\hline
\end{tabular}


Table (3):Practices of the studied PHC* physicians as regards screening for HTN** versus their sociodemographic data

\begin{tabular}{|c|c|c|c|c|c|c|c|c|c|c|c|c|}
\hline \multirow{3}{*}{$\begin{array}{l}\text { Sociodemo- } \\
\text { graphic Data }\end{array}$} & \multicolumn{10}{|c|}{ Practices regarding screening for HTN (Yes answers) } & & \\
\hline & \multicolumn{2}{|c|}{$\begin{array}{l}\text { Performing } \\
\text { enough and } \\
\text { accurate } \\
\text { procedures to } \\
\text { diagnose } \\
\text { hypertensive } \\
\text { cases? }\end{array}$} & \multicolumn{2}{|c|}{$\begin{array}{l}\text { routine } \\
\text { checking up } \\
\text { the } \\
\text { accuracy of } \\
\text { the used } \\
\text { sphygmoma } \\
\text { nometers. }\end{array}$} & \multicolumn{2}{|c|}{$\begin{array}{l}\text { Measuring } \\
\text { blood pressure } \\
\text { every time the } \\
\text { hypertensive } \\
\text { patient attends } \\
\text { the clinic? }\end{array}$} & \multicolumn{2}{|c|}{$\begin{array}{c}\text { Routine } \\
\text { screening HTN } \\
\text { for patients } \\
\text { around } 40 \text { years } \\
\text { old? }\end{array}$} & \multicolumn{2}{|c|}{$\begin{array}{c}\text { Regular } \\
\text { measuring } \\
\text { BP*** for } \\
\text { patients with } \\
\text { risky factors? }\end{array}$} & \multicolumn{2}{|c|}{ Total } \\
\hline & $\mathbf{N}$ & & $\mathbf{N}$ & & $\mathbf{N}$ & $\%$ & $\mathbf{N}$ & $\%$ & $\mathbf{N}$ & $\%$ & $\mathbf{N}$ & $\%$ \\
\hline AGE (years) & & & & & & & & & & & & \\
\hline 0 & 36 & 67.9 & 23 & 43.4 & 49 & 92.5 & 27 & 50.9 & 45 & 84.9 & 53 & 100.0 \\
\hline 40- & 29 & 60.4 & 18 & 37.5 & 42 & 87.5 & 16 & 33.3 & 42 & 87.5 & 48 & 100.0 \\
\hline $\mathbf{P}^{* * *} \begin{array}{c}50+ \\
\text { value }\end{array}$ & 11 & 61.1 & 11 & $2^{61.1}$ & 17 & 94.4 & 12 & 66.7 & 12 & 66.7 & 18 & 100.0 \\
\hline Total & 76 & 63.9 & 52 & 43.7 & 108 & 90.8 & 55 & 46.2 & 99 & 83.2 & 119 & 100.0 \\
\hline$\underline{\text { SEX }}$ Male & 28 & 62.2 & 23 & 51.1 & 39 & 86.7 & 18 & 40.0 & 37 & 82.2 & 45 & 100.0 \\
\hline $\begin{array}{l}\text { Female } \\
\text { P-value }\end{array}$ & 48 & 64.9 & 29 & $2^{39.2}$ & 69 & 93.2 & 37 & 50.0 & 62 & 83.8 & 74 & 100.0 \\
\hline Total & 76 & 63.9 & 2 & 43.7 & 108 & 90.8 & 55 & 46.2 & 99 & 83.2 & 119 & 100.0 \\
\hline$\frac{\text { DEGREE }}{\text { MBBCH }}$ & 45 & 63.4 & 36 & 50.7 & 67 & 94.4 & 36 & 50.7 & 58 & 81.7 & 71 & 100.0 \\
\hline Higher & 31 & 64.6 & 16 & 33.3 & 41 & 85.4 & 19 & 39.6 & 41 & 85.4 & 48 & 100.0 \\
\hline P-value & & & & 6 & & & & & & & & \\
\hline Total & 76 & 63.9 & 5 & 43.7 & 108 & 90.8 & 55 & 46.2 & 99 & 83.2 & 119 & 100.0 \\
\hline$\frac{\text { Experience }}{\text { ar) }}<10$ & 16 & 51.6 & 13 & 41.9 & 28 & 90.3 & 17 & 54.8 & 24 & 77.4 & 31 & 100.0 \\
\hline P-value ${ }^{10+}$ & 60 & $9^{68.2}$ & 39 & $8^{44.3}$ & 80 & 90.9 & 38 & 43.2 & 75 & 85.2 & 88 & 100.0 \\
\hline Total & 76 & 63.9 & 52 & 43.7 & 108 & 90.8 & 55 & 46.2 & 99 & 83.2 & 119 & 100.0 \\
\hline
\end{tabular}

*PHC = primary health care

**HTN=Hypertension

****The statistical test used was $\mathbf{x}^{2}$ 


\section{Ayman S. Abdelhady}

\section{Discussion}

The majority of the participating physi-cians in the study had a reasonable level of favorable attitude towards screening patie-nts for different items of (HTN) except that concerning job satisfaction inside the PHC clinics (Table 2), where just little more than half of the physicians showed job satisf-action especially in dealing with chronic diseases as HTN . A study conducted in "Lithuania", revealed that total job satisfac-tion of doctors working at primary health care settings is relatively low, and compensation, social status, and workload are among the key factors that stand behind the PHC doctors' dissatisfaction with their job (Buciuniene et al., 2005) (PHC) providers, in many circumstances, reported feeling frustrated about not having enough time or having difficulties in explaining preventive care and chronic disease management to many of their patients (Simoens et al., 2002).

As regards the accuracy of knowledge towards the items of (HTN), it was found that most of the participating physicians $(85.7 \%)$ knew the old definition and grading of HTN, while only (18.5\%) knew the most recent definition and grading and $(23.5 \%)$ knew the prevalence of HTN .In a study conducted in Saudi Arabia, only (28\%) of the studied doctors knew the correct definition of HTN and a similar results were obtained as regards the prevalence and complications of HTN .The researchers considered that as a serious defect as regards these important questions in (HTN), and they attributed that to doctors who may follow another definition of (HTN) other than the most recent one (the old one) (Al- Khashman ,2002).

Findings like that may emphasize the need for a continuing training to improve the PHC doctors awareness towards different items of (HTN) especially definition and etiology, and this in turn would improve the early detection and management of cases. Continuing medical education programs should also tackle this defect (Kalantan et al., 2001).Some researchers suggested quality assurance manual to be available for PHC doctors and this would be helpful in management of chronic diseases (Ben-Shlomo and Kuh, 2002).

It is hoped that this new classification of pre-hypertension will serve as an educational tool to signal the need for increased education of health care providers and the public to use all efforts to reduce BP levels and prevent the development of hypertension ( Mohammad et al., 2004 ).

The younger doctors in the present study had mostly a better knowledge than the older ones.This finding conforms with what reported recently that doctors knowledge is almost reduced after 10 to 15 years of experience without updating their skills ( Al- Khashman ,2002).

The practices of the participating physicians goes in parallel with their knowledge and showed some unsatisfactory aspects, where less than two thirds of the physicians $(63.9 \%)$ reported that they usually provide enough diagnostic procedures for chronically ill patients including HTN, and only (43.7\%) were assured of the accuracy of the used sphygmomanometers, while less than half of the studied physicians $(46.2 \%)$ routinely measure BP of patients who are around forty years old. Schmittdiel et al. (2006) stated that highquality chronic illness care is difficult to achieve in primary care settings especially when the system centres on treating acute illnesses and work in ( PHC) settings commonly and frequently complains of shortages and inadequacies .

Most health care, particularly at the PHC level, is currently organized around an acute and episodic model of care - a model that does not meet the needs of many patients, especially older patients with chronic diseases (WHO, 2001).

Studies carried out on HTN, and other chronic diseases as diabetes mellitus in primary health care settings have collectively concluded that chronic diseases were not adequately screened for, and patients were not appropriately controlled 
and many cases may pass undiscovered (Whelton et al., 2002).

One of the most significant barriers to health care is lack of trained health care providers .Training is linked to attitude and skills and directly correlates with the quality of care provided and therefore to the outcome of care (Bonomi et al., 2002) .

Health care providers themselves discussed their need for training in diagnosing the complex symptoms of chronic care, managing several conditions at once and choosing appropriate treatments and medications for patients (WHO, 2001).

The survey of more than 6,000 primary care physicians in Australia, Canada, Germany, the Netherlands, New Zealand, the United Kingdom, and the United States revealed that a high proportion of doctors in these countries (25\% to $30 \%$ or more), except Germany (7\%), said they are not well-prepared to care for patients with multiple chronic conditions including hypertension . primary care physicians in the U.S. do not have the tools or support to provide the best care possible to patients with chronic disease ( Schoen et al., 2006 ). Primary care physicians in many countries share many common challenges, among them improving coordination of care for patients with chronic disease ( WHO ,2003).

Many doctors, nurses and other providers did not work effectively as a team, resulting in gaps in communication, assessment and treatment and inefficient use of scarce manpower resources ( Sibbald et al., 2003).

Lack of resources across the board, including insufficient numbers of trained staff and diagnostic services, funding as well as money to upgrade centres, all lead to overburdened staff with insufficient time for a caring and comprehensive examination ( WHO, 2001).

In conclusion: though, the physicians of the current study have a good level of favorable attitude towards screening patients for HTN, they had an unsatisfactory practices and low knowledge regarding some important items and up-to-date information of HTN. The study recom- mended that PHC physicians are in need of more continuing medical education to improve their knowledge and practice towards HTN, available local and international manuals as regards dealing with chronic diseases should be made accessible and workshops and seminars on how to make use of these guidelines would improve doctors' performance.

\section{References}

1. 1-Alaszewski A, Billings J, Coxon $\mathbf{K}$ (2004): Integrated health and social care for elder persons: theoretical and conceptual issues. In: Leichsenring $\mathrm{K}$,Alaszewski A, eds. Providing integrated health and social care for older persons: a European overview of issues at stake. Aldershot, Ashgate Publishing: 53-94.

2. 2-Al-Khashman A.S. (2002): Screening for Hypertension in Al-Riayd region Kingdom of Saudi Arabia Saudi Med. J. 22 (12):1096-1100.

3. Baicker K, Chandra A (2004): Medicare spending, the physician workforce, and beneficiaries' quality of care. Health Aff (Millwood). 2004; Suppl Web Exclusive: W184-W197.

4. Ben-Shlomo Y, Kuh D (2002): A life course approach to chronic disease epidemiology :conceptual models, empirical challenges and interdisciplinary perspectives. International Journal of Epidemiology, 31:285-293.

5. Bodenheimer $\mathbf{T}$, Wagner $\mathbf{E} \mathbf{H}$, Grumbach K (2002): Improving primary care for patients with chronic illness. JAMA., $288: 1775-1779$.

6. Bonomi AE, Wagner EH, Glasgow RE, VonKorff $M$. (2002): Assessment of chronic illness care (ACIC): a practical tool to measure quality improvement. Health Serv Res., 37: 791-820.

7. Buciuniene I. , Blazeviciene A. and Bliudziute E., (2005): Health care reform and job satisfaction of primary health care physicians in Lithuania BMC Family Practice , 6:10-15.

8. El-Khashab O,(2002) : Hypertension and End-Stage Renal Disease in the Developing World. Artificial Organs 26 (9): 765-766.

9. Ibrahim M,(1996): Future of research in hypertension in developing countries. 
Eastern Mediterranean Health J. (2) 2: 202205.

10. Kalantan KA, Mohamed AG, Al Taweel AA , and Abdulghani HM (2001): Hypertension among attendants of Primary Health Care in Al - Qassim Region, Saudi Arabia .Saudi Medical J., (22)11:960-963.

11. Khalil H, (1997): Hypertension in elderly Egyptians. Eastern Mediterranean Health J., (2) 2:206-210.

12. Macinko J, Starfield B, Shi L (2003): The contribution of primary care systems to health outcomes within Organization for Economic Cooperation and Development (OECD) countries, 1970-1998. Health Serv Res. , 38: 831-865.

13. Mohammad Y, Qureshi AI, and Suri MFK. (2004): Is pre-hypertension a risk factor for stroke and myocardial infarction? Program and abstracts from the 29th International Stroke Conference; February 5-7; San Diego, California.

14. National Heart, Lung, and Blood Institute, US (1993): Fifth Report of the Joint National Committee on Prevention, Detection, Evaluation, and Treatment of High Blood Pressure (JNCV). Philadelphia, Md..Arch. Intern. Med ., 153 :154-158.

15. National Heart, Lung, and Blood Institute, US (2004): Seventh Report of the Joint National Committee on Prevention, Detection, Evaluation, and Treatment of High Blood Pressure (JNC 7). Rockville, Md. Department of Health and Human Services; August 2004. National Institutes of Health Publication No. 04-5230.

16. Schmittdiel JA, Shortell SM, Rundall TG, Bodenheimer T, and Selby V.(2006) : Effect of Primary Health Care Orientation on Chronic Care Management .Annals of Family Medicine., 4:117-123.
17. Schoen C, Osborn R, Trang Huynh P, Doty M, Peugh J, Zapert K: (2006) :On The Front Lines of Care: Primary Care Doctors' Office Systems, Experiences, and Views in Seven Countries, Health Affairs Web Exclusive (Nov. 2, 2006):w555w571.

18. Sibbald B, Bojke C, Gravelle H (2003): National survey of job satisfaction and retirement intentions among general practitioners in England. BMJ.;4: 326-329.

19. Simoens S, Scott A, Sibbald B (2002): Job satisfaction, work-related stress and intentions to quit of Scottish GP.Scott Med J, 47(4):80-6.

20. Wang Y, Wang QJ(2004): The prevalence of prehypertension and hypertension among US adults according to the new joint national committee guidelines: new challenges of the old problem. Arch. Intern. Med. , 164 (19) :2126-34.

21. Whelton PK, He J, Appel LJ,(2002 ): Primary prevention of hypertension : Clinical and public health advisory from The National High Blood Pressure Education Program.JAMA., 288(15):18821884.

22. WHO (2003): Primary health care: a framework for future strategic directions. Global report.Geneva, World Health Organization (WHO/ MNC/ OSD/ 03.01;http://www.who.int/chronic_conditio ns/primary_health_care/en/phc_report_oct0 3.pdf, accessed 22 June 2004).

23. WHO (2001):Innovative care for chronic conditions : meeting report, 30-31 May 2001. Geneva, World Health Organization (WHO / MNC / CCH/01.01; http:// whqlibdoc. who.int/hq/2001/WHO -MNCCCH-01.01.pdf, accessed 22 June 2004). 


\section{"دراسة مقطعية لاستبيان ملى معرفة أطباء الرعابية الصحية الأولية بأهمية

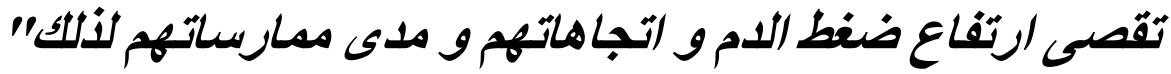 أيمن سبد عبد الهادى الهي \\ قسم طب المجتمع كلية طب الأزهر}

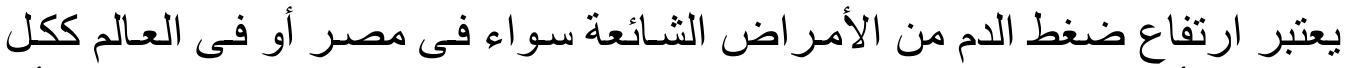

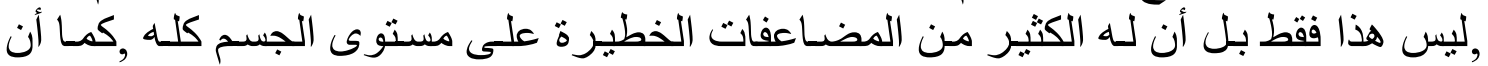

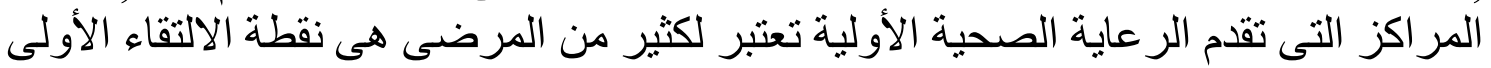

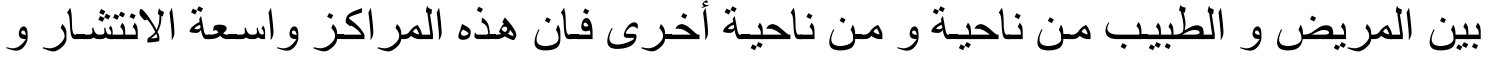
تغطى قطاعات و اسعة من الناس.

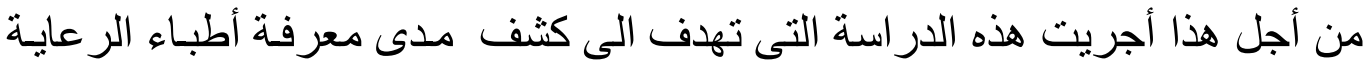

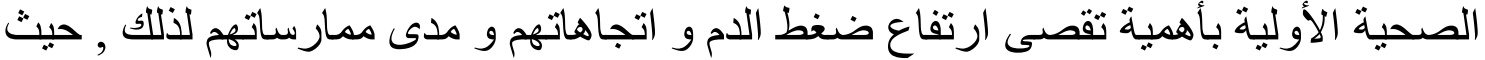

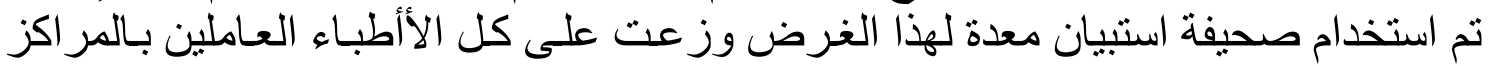

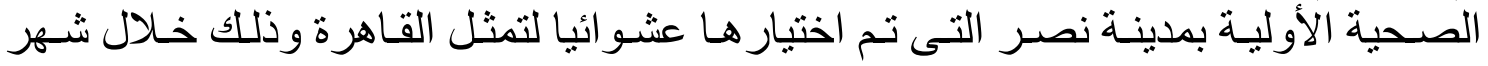
ديسمبر 2005 .

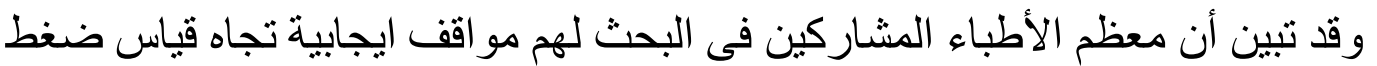

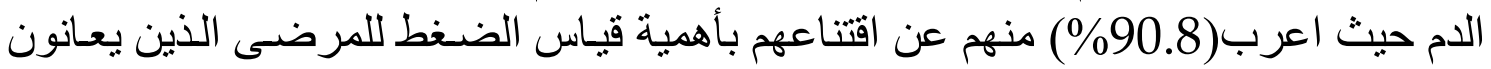

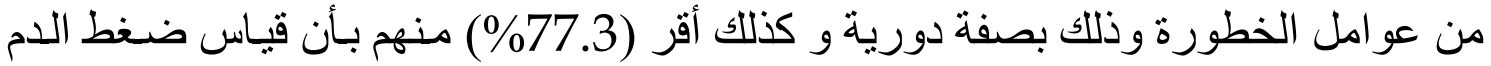

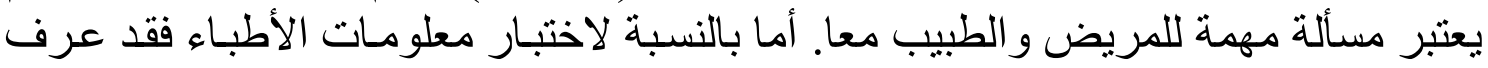

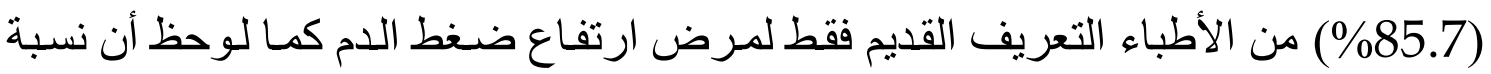

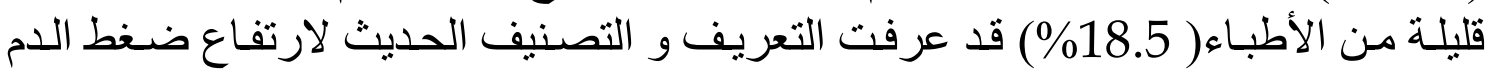

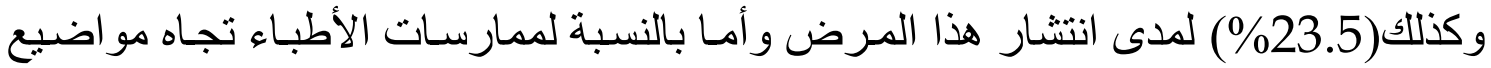

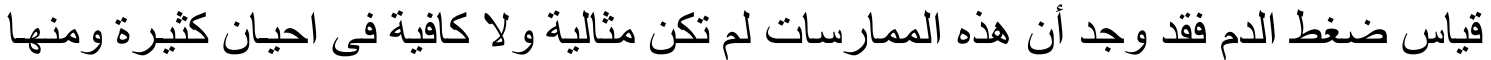

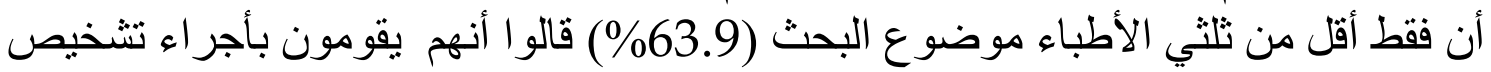

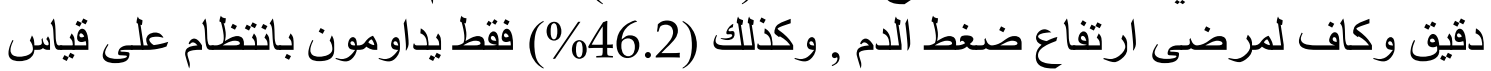

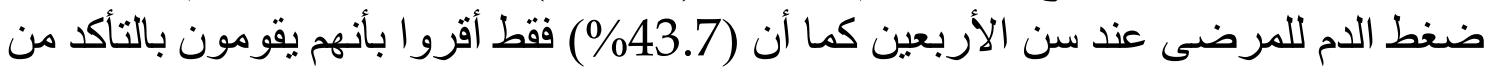

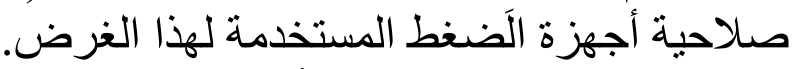

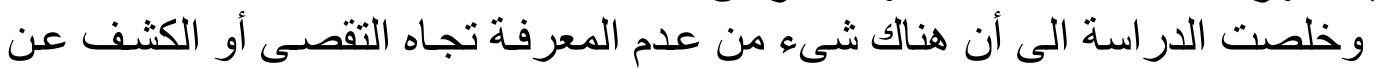

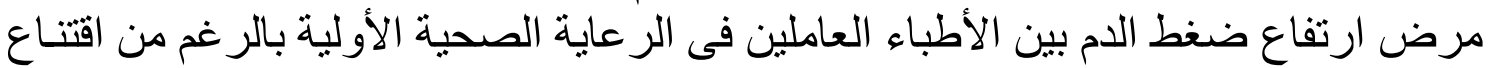

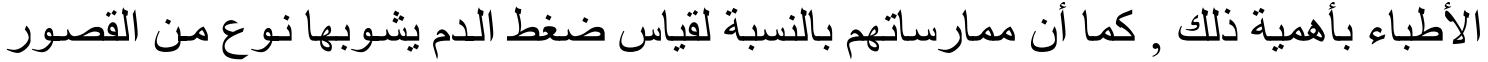

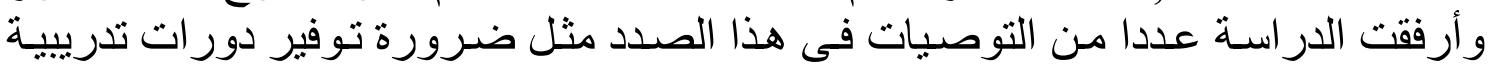

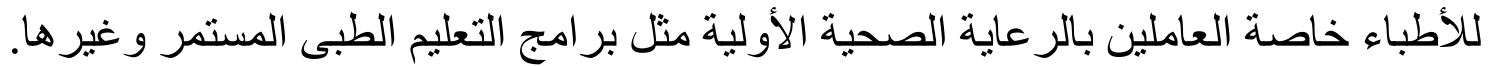

